\title{
๖The Grounding of Floating Objects in a Marginal Sea
}

\author{
R. PAWLOWICZ ${ }^{\mathrm{a}}$ \\ ${ }^{a}$ Department of Earth, Ocean, and Atmospheric Sciences, The University of British Columbia, Vancouver, \\ British Columbia, Canada
}

(Manuscript received 9 August 2020, in final form 22 October 2020)

\begin{abstract}
Beaches, especially at or above the high tide line, are often covered in debris. An obvious approach to understanding the source of this debris elsewhere in the ocean is to use Lagrangian methods (observationally or in numerical simulations). However, the actual grounding of these floating objects, that is, the transition between freely floating near the coast and motionless on land, is poorly understood. Here, 800 groundings from a recent circulation project using expendable tracked drifters in the Salish Sea are statistically analyzed. Although the grounding process for individual drifters can be complex and highly variable, suitable analyses show that the complications of coastlines can be statistically summarized in meaningful ways. The velocity structure approaching the coastline suggests a quasi-steady "log-layer" associated with coastline friction. Although groundings are marginally more likely to occur at higher tides, there are many counterexamples and the preference is not overwhelming. The actual grounding process is then well modeled as a stationary process using a classical eddy-diffusivity formulation, and the eddy diffusivity that best matches observations is similar to that appearing in open waters away from the coast. A new parameter in this formulation is equivalent to a mean shoreward velocity for floating objects, which could vary with beach morphology and also (in theory) be measured offshore. Finally, it appears that currently used ad hoc beaching parameterizations should be reasonably successful in qualitative terms, but are unlikely to be quantitatively accurate enough for predictions of grounding mass budgets and fluxes.
\end{abstract}

KEYWORDS: North Pacific Ocean; Dispersion; Lagrangian circulation/transport; Subgrid-scale processes; Trajectories

\section{Introduction}

Beaches, especially at or above the high tide line, are often covered with debris. This includes logs and seaweed, plastics (Kako et al. 2014; Jambeck et al. 2015), oil from oil spills (Spaulding 2017), fishing gear, or even, on occasion, aircraft parts (Jansen et al. 2016) or remains (Ebbesmeyer and Haglund 2002; Irfan 2019). This debris comes from somewhere else, and an obvious approach to understanding the transport of such material in the ocean is to use Lagrangian methods: tracking actual drifters (LaCasce 2008; Lumpkin et al. 2017), or pseudodrifters whose trajectories are predicted using numerical circulation models (Van Sebille et al. 2018).

Strangely, the actual grounding of these floating objects, that is, the transition between freely floating near the coast and motionless on land, is poorly understood. Most numerical drifter codes, if they include beaching at all, (e.g., Zelenke et al. 2012; Fernandes et al. 2013; Lange and van Sebille 2017) implement one or more plausible but ad hoc approaches to predicting the beaching of particles, relying on tuning parameters to adjust the results until they fit a particular dataset. Analysis of large observational datasets (as in Lumpkin et al. 2012) is almost nonexistent.

Recently, technological advances have dramatically decreased the cost of satellite-tracked and monitored drifters

¿ Denotes content that is immediately available upon publication as open access.

Corresponding author: Rich Pawlowicz,rich@eos.ubc.ca down to as little as $\approx 150$ USD each for parts, making longer deployments of large numbers of expendable drifters much more feasible. A modestly funded circulation project in the Salish Sea (Fig. 1) using 406 such drifters gathered about 2200 drifter days of data with tracks observed at 5 -or 10-min intervals (more than $3 \times 10^{5}$ recorded positions; Pawlowicz et al. 2019). An unexpected result of this project was the finding that drifters tended to ground rather rapidly, within a few days of deployment (on average) in this system, much less than residence times for the estuarine circulation. Grounded drifters often refloated days or weeks later, and then could reground. The drifter dataset then includes detailed observations of 801 groundings.

This relatively large set of observations (relative, to, say, the seven groundings in Meyerjürgens et al. 2019) allows for the development of reasonably robust statistical analyses. Since individual groundings are (one would think) strongly dependent on local conditions, an a priori assumption that coherent statistical structures underlie this process over wider areas may seem unwarranted at this point, but such an assumption has proved useful in previous studies of other complex systems, e.g., turbulent boundary layers over rough surfaces (Schlichting and Gersten 2017), and, as will be shown below, it appears to have relevance for the grounding problem as well.

The purpose of this paper, then, is to statistically characterize the behavior of drifters near coastlines, including the manner in which drifters ground. Although limited to a particular geographic area, with no guarantee that similar results might be found in other areas, the analysis at least provides a general framework for understanding the grounding process and improving its parameterizations. 

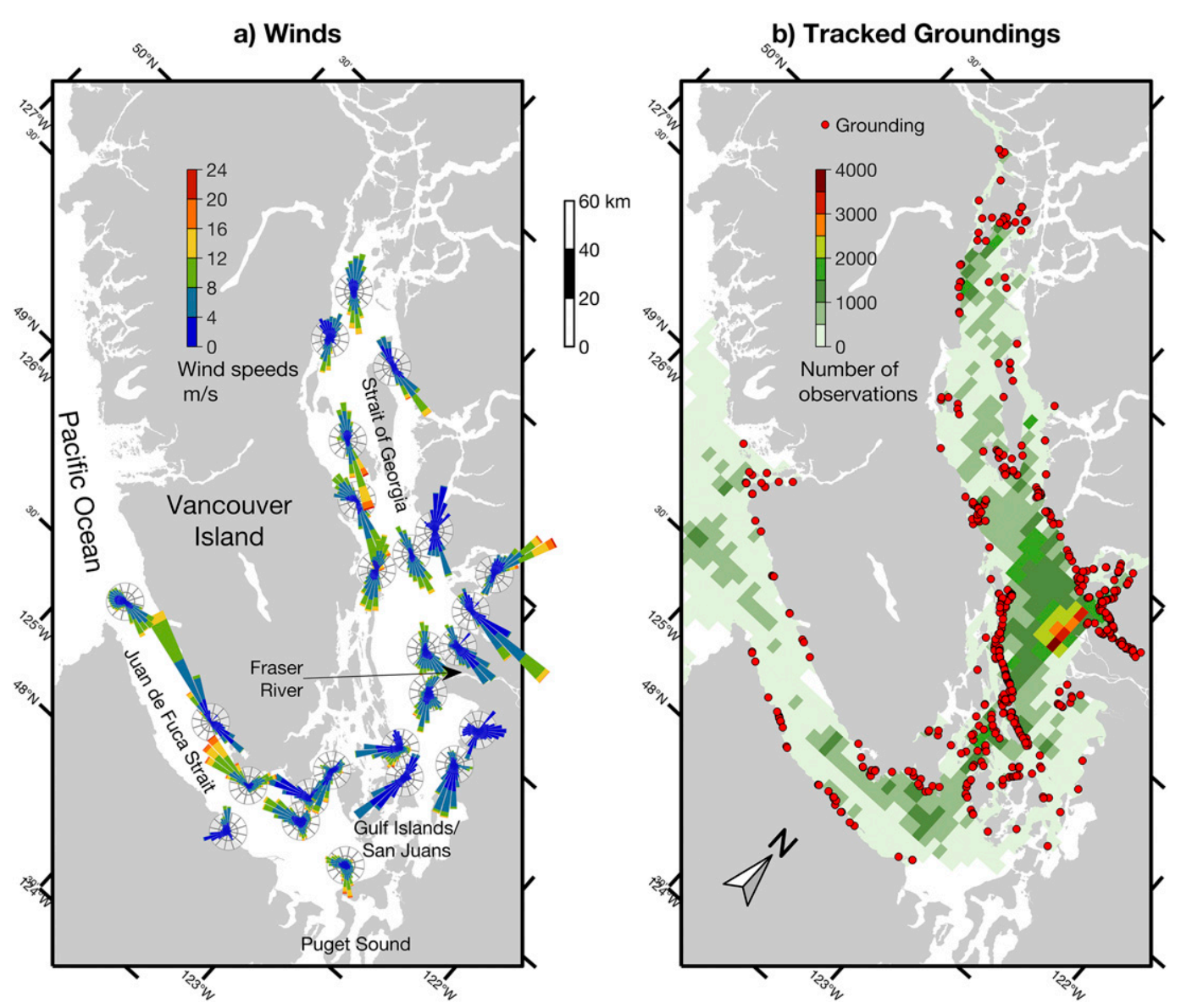

FIG. 1. Salish Sea region, with (a) wind roses for annual observed winds at locations with permanent weather stations. Rings are at $2 \%$ and $4 \%$. (b) Locations of tracked groundings, as well as the density of category 1 observations (numbers per $0.05^{\circ} \times 0.05^{\circ}$ bins).

\section{Methods}

\section{a. Site}

The Salish Sea (Fig. 1a) is a large estuarine system, about $400 \mathrm{~km}$ long $\times 25 \mathrm{~km}$ wide with an average depth of more than $100 \mathrm{~m}$, separated from the northeastern Pacific Ocean by Vancouver Island. It includes both open waters (the Straits of Georgia and Juan de Fuca) as well as more constricted regions containing many islands (the southern Gulf Islands and San Juans). The water column is generally well stratified near the surface, due to a significant inflow of freshwater from the Fraser River and other rivers (Pawlowicz et al. 2007; Masson 2006), although vigorous tidal flows result in localized patches of intense mixing and weak stratification. There are a few regions within the Salish Sea where beaches shoal gradually, but at most locations the water gets deep quite rapidly, with the $20-\mathrm{m}$ isobath only $O(200) \mathrm{m}$ offshore. Average seaward flow speeds on the surface resulting from the estuarine circulation are $O(0.1) \mathrm{m} \mathrm{s}^{-1}$ (Pawlowicz et al. 2019), but tides and winds result in a mean drifter speeds of $0.34 \mathrm{~m} \mathrm{~s}^{-1}$, averaged over the whole dataset used here. Highest instantaneous speeds at some locations approach $2 \mathrm{~m} \mathrm{~s}^{-1}$.
Seasonal mean surface winds in the Salish Sea are generally only a few meters per second. Within the Strait of Georgia winds are less than $5 \mathrm{~m} \mathrm{~s}^{-1}$ for at least $50 \%$ of the time during which the surface Stokes drift, a mean transport that arises from periodic wave action, has been found to be essentially zero (Gemmrich and Pawlowicz 2020). Winds are only greater than $10 \mathrm{~m} \mathrm{~s}^{-1}$, with associated wave heights of $1-2 \mathrm{~m}$ and surface Stokes drifts of $>0.07 \mathrm{~m} \mathrm{~s}^{-1}$, for $6 \%$ of the time. However, the Stokes drift decays rapidly with depth, and since the drifters used here are drogued below the surface they will only be partly affected by even these small surface drift terms.

Not only are the Stokes drift speeds low, but the steep topography on both coastlines directs the surface winds (and waves) mostly along-Strait (Fig. 1a) and not onshore, although the nearshore wave field will turn in that direction as depths decrease. Stokes drift is therefore probably unimportant to the grounding process here, although it is an important factor governing drifter motions in the open ocean (Van Sebille et al. 2020).

Juan de Fuca Strait is open to the Pacific and winds are slightly stronger there. More critically, it is not sheltered from long-period oceanic swell and wave heights are typically $1-2 \mathrm{~m}$, 
although they can be as much as $8 \mathrm{~m}$ at its western end (Yang et al. 2019) so that Stokes drift speeds may be larger than in the Strait of Georgia. However, winds and waves are again directed along the Strait by the height of land on either side.

\section{b. Drifter design}

Two types of high-resolution expendable surface drifter were used for this work (Fig. 2). Both are more fully described and their performance evaluated at length in Pawlowicz et al. (2019) and Page et al. (2019). One drifter design ("UBC," designed at the University of British Columbia) was optimized for measuring average currents in the upper $50 \mathrm{~cm}$ of the water column, and consists of flat wooden floats above a rigid crossshaped drogue of sheet metal about $50 \mathrm{~cm}$ across and $40 \mathrm{~cm}$ tall (cross-sectional area $\sim 1800 \mathrm{~cm}^{2}$ ). The second drifter design, the Surface Circulation Tracker ("SCT," designed by Fisheries and Oceans Canada), consists of a cylindrical surface float made of biodegradable cellulose foam with a weighted and drogued vertical wooden spar hanging $38 \mathrm{~cm}$ deep below the float to prevent its overturning, the float and drogue have a cross-sectional area $\sim 450 \mathrm{~cm}^{2}$. Although drogues are rigidly mounted, repeated field tests have shown no sign of the anomalous wave-induced drifts reported by Novelli et al. (2017) for a somewhat similar design.

Both drifter types were designed to use a commercially available asset tracker (the SPOT Trace, SPOT LLC, Louisiana) which can report Global Positioning System (GPS)-derived positions on a regular 5- or 10-min schedule using the Globalstar constellation of low-Earth-orbit satellites when "woken" by vibration. To reliably vibrate the unit by magnifying water motions, it is mounted at the top of a $10-\mathrm{cm}$ vertical spring; this also raises the tracker about $10 \mathrm{~cm}$ above water level.

Tests on land, with the trackers oriented upward with an unobstructed view of the sky, find that the standard error in reported positions from the trackers is about $\pm 2.5 \mathrm{~m}$, uncorrelated from fix to fix. However, grounded drifters are often on their side, so that the tracker antenna is oriented sideways, or even (due to bending of the mounting spring) slightly inverted, and multipath reflections of the GPS signal from rocky surroundings can lead to additional signal degradation. The scatter in positions while grounded is sometimes an order of magnitude larger (see, e.g., Fig. 3a); many gaps in the position time series also occur when grounded due to a lack of vibration.

\section{c. Drifter track processing}

The interactions of drifters with land can be quite complicated (Lumpkin et al. 2012), and this is even more true at the very small spatial scales typical of estuaries. Some examples from the dataset are shown in Fig. 3. Thus, all drift tracks were carefully and manually examined, with position fixes along tracks classified into four categories.

Category 1 , the majority, includes all points in which the drifter is moving freely at sea ("valid"). Category 4 includes points that are "bad" (i.e., when being carried on vessels, stuck to towed objects, being transported on land, or which are clearly the results of a rare bad position fix, identified by unrealistic speeds to a far-away position and its almost immediate return).

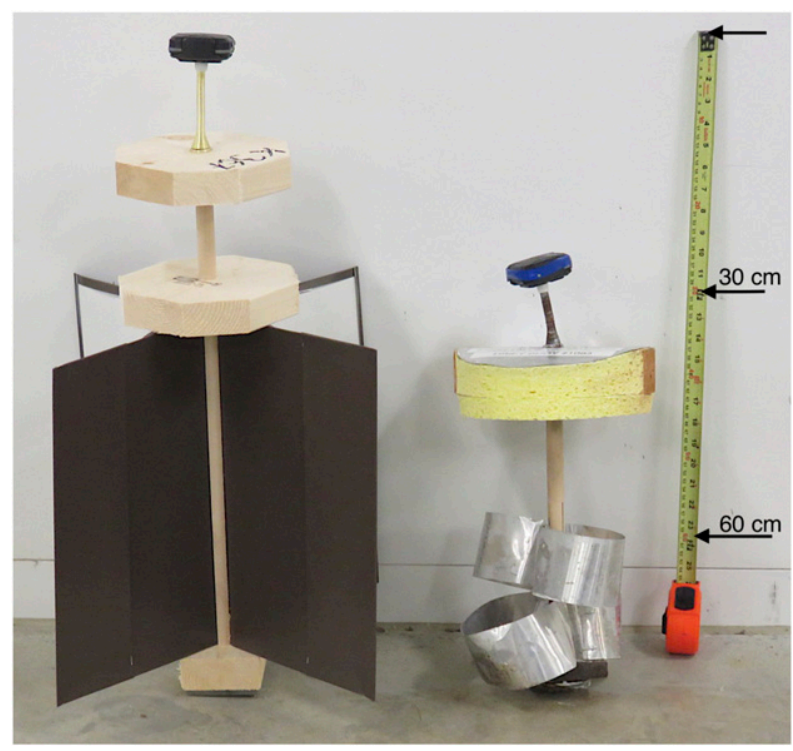

FIG. 2. Drifter designs: (left) UBC and (right) SCT. The surface floats are mostly below waterline, with the SPOT trackers about $10 \mathrm{~cm}$ above waterline on a mounting spring.

Careful visual examination of tracks plotted on submeterscale high-resolution Google Maps optical satellite imagery suggests a variety of possible interactions with land, depending on tidal height, beach slope, and the small-scale topography of the region. Although motionless grounding is sometimes obvious (e.g., Fig. 3a), at other times, due to random errors in positioning, the apparent speed of "stationary" drifters drops to a low value, but not lower than water velocities sometimes seen when obviously floating even when quite close to land (e.g., Fig. 3c). Abrupt changes in directionality of velocities from fix to fix can sometimes but not always separate these cases. Drifters rolling in the swash zone of gently sloping beaches can also move slowly and steadily up and across the beach with the rising tide (e.g., Fig. 3d). Alternatively, drifters can move steadily and freely within a few meters of rocky coastlines where depths increase rapidly. Drifters at other times seem to stop moving at locations hundreds of meters offshore, apparently stuck in what are likely large kelp patches, or in rocky reefs (e.g., Fig. 3b).

Two categories are therefore used to classify interactions with land. Category 3 ("grounded") is used for points at which the drifter, even if moving, is judged to be mostly grounded (i.e., largely or fully touching a solid boundary). Category 2 ("trapped" or "intertidal") is used for points in which the drifter is judged to be mostly floating, but not moving freely. This includes drifters trapped in tidal pools, against cliffs, or within kelp fields.

An interactive computer code DRIFTEVAL was developed to assist in the classification process, allowing analysts to simultaneously see tracks overlaid on coastlines and satellite imagery, speeds, time series (to identify gaps when the sensor was not sufficiently vibrating), and the tidal height. For the analysis in this paper the first in a series of either category 2 or category 3 points is considered a grounding location. 

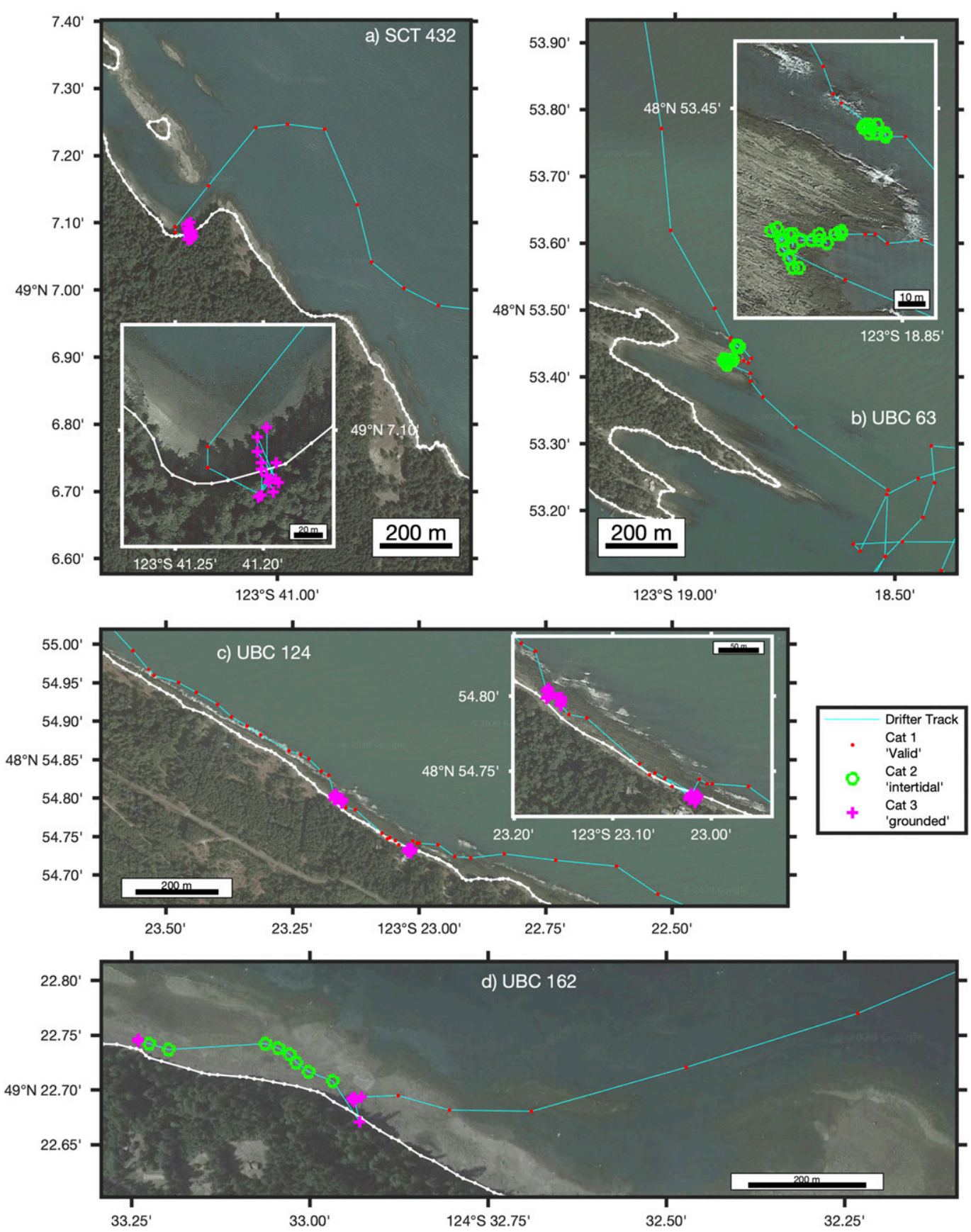

FIG. 3. Grounding examples with point classifications. Background images are from Google Maps, and the white line joins points in the high-resolution coastline. (a) The standard case, grounding at high tide on a rocky beach. Inset illustrates the typical increased variability in observed positions when grounded, perhaps because the sky is partially obscured. (b) A rocky shelf offshore traps the drifter twice as it moves southeastwards, for most of a rising tide. Inset shows slow movements at this time; the drifter is still floating but trapped against the rocks. (c) A drifter moving ESE along a coast with a narrow rocky shoreline grounds twice on a rising tide (surf line in imagery is likely at low tide). After the second grounding it remains grounded for an entire tidal cycle, before refloating and continuing. (d) Grounding on an extensive shallow and sandy beach (possibly still visible through the water far offshore), the drifter is then moved further westward along the beach in a swash zone before its final grounding. 

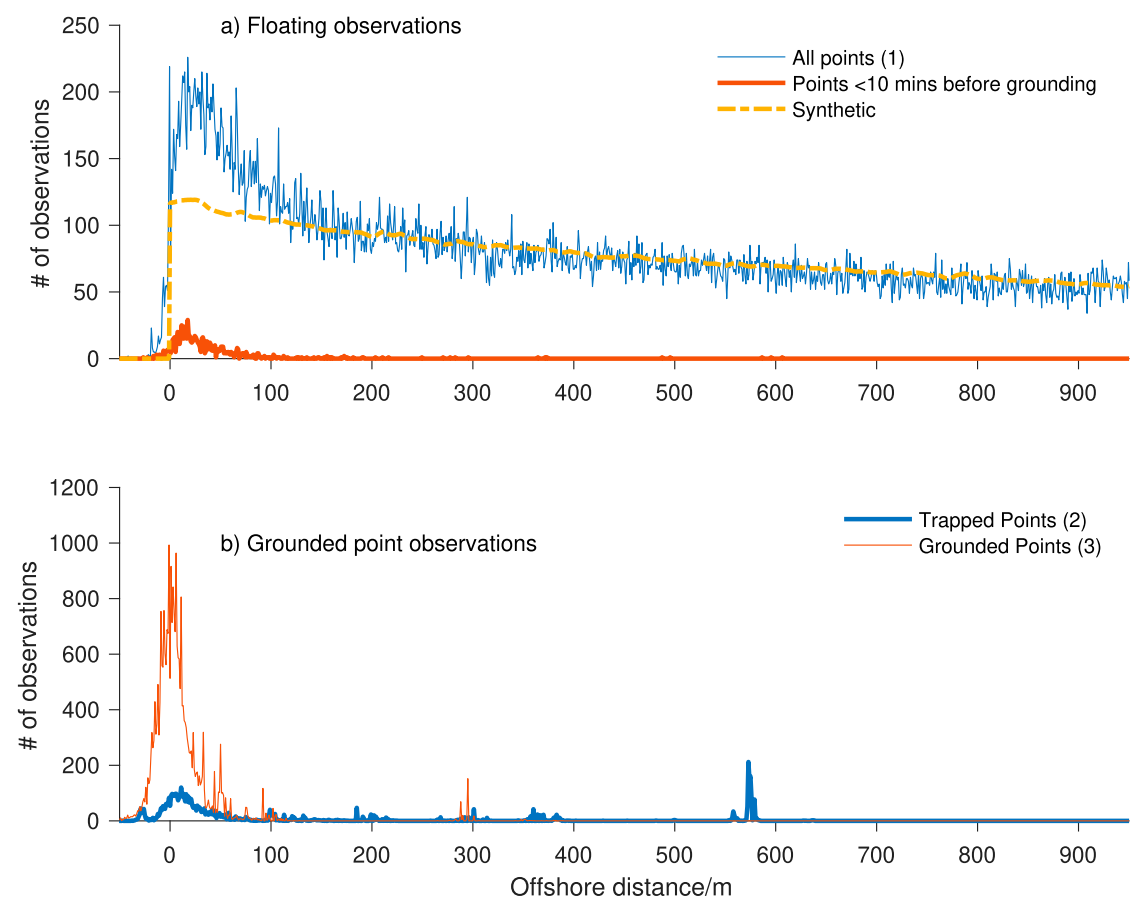

FIG. 4. Distribution of observations with distance from shore. (a) The distribution of all category 1 ("valid") observations, and observations within $10 \mathrm{~min}$ of grounding. The synthetic distribution is scaled to match the height of the observed distribution at large distances. (b) Grounded category 2 (floating but trapped) and 3 (fully grounded) points.

\section{d. Other data sources}

The Salish Sea lies between Canada and the United States. High resolution coastlines with points spaced $O(20) \mathrm{m}$ apart were obtained for both countries, and converted to a common datum using M_Map software (Pawlowicz 2019). They were then merged and arranged in oriented closed curves with land on the right hand side of segments outlining each island as the curve is traversed. Arbitrary points can therefore easily be classified as being either inshore or offshore of the nearest line segment depending on whether they are to its right or left. Further information about these coastlines is not available; in particular, their relationship with the location of the high tide line is not clear.

Sea level information is obtained from SalishSeaCast, an operational numerical model for this region. SalishSeaCast is a NEMO 3.6 configuration (Soontiens et al. 2016; Soontiens and Allen 2017) with 40 vertical levels and a horizontal resolution of about $500 \mathrm{~m}$. Hindcast simulations are forced by winds from the Environment and Climate Change Canada 2.5-km resolution HRDPS (High Resolution Deterministic Prediction System) atmospheric model (Milbrandt et al. 2016), by river forcing through a mix of climatological and available gauged measurements from 149 rivers, and at the open boundaries through a mix of analyzed tides and measured subtidal sea surface height variations.

\section{Results}

Over the years 2015-18, 164 UBC and 242 SCT drifters were released from different locations into the Salish Sea in about
30 different deployments (the actual number of trackers expended was much smaller than this total, as about two-thirds of all deployed trackers were eventually recovered after grounding and reused, sometimes multiple times). Most of the deployments were in summer, although wintertime deployments also occurred. Although UBC drifters were released mostly in the Strait of Georgia, many SCT drifters were released elsewhere in the Salish Sea. An analysis of large-scale circulation patterns based on this dataset is detailed in Pawlowicz et al. (2019). Here a total of 801 groundings were identified from 290 drifters (Fig. 1b). Although category 1 drifter observations at sea and category 2 and 3 grounding locations tend to be in the southern Strait of Georgia, they are distributed over the whole region, with the exception of Puget Sound and some other inlets. Penetration into the islands that block off the northern Salish Sea was minimal.

\section{a. Distance to the coast}

For all drifter locations, distance to the nearest land was obtained by an exhaustive search for the nearest point in the high-resolution coastline, after linearly interpolating this coastline to points $2 \mathrm{~m}$ apart. Approximately 100 category 1 observations were found for every $1-\mathrm{m}$ interval of offshore distance, within $1000 \mathrm{~m}$ of land (Fig. 4a). The distribution of observed distances slopes gradually for distances of greater than $100 \mathrm{~m}$, but rises sharply at smaller distances. Although one would expect a step-like drop-off in the distribution at a distance of $0 \mathrm{~m}$, ambiguity in the coastline definition leads to a steep, but not instant, drop-off. Drifter observations, although 
mostly offshore, were sometimes inshore of the defined coastline while judged to be afloat, or offshore while grounded (e.g., Fig. 3c).

The effects of this coastline ambiguity are more obviously evident in the distribution of category 3 grounded points (Fig. 4b). This distribution is not a single spike, but rather occupies a roughly Gaussian-shaped region over distances from -25 to $25 \mathrm{~m}$. There are also a few outliers at much greater distances related to large rocky shelves, obvious in satellite imagery but excluded from the coastlines. However, the mode or peak of the distribution occurs at an offshore distance of only a few meters. There are fewer category 2 points, but the mode of the distribution for this category occurs at about $10 \mathrm{~m}$ offshore (again, with some outliers at large distances that were mostly associated with drifters that stopped moving in kelp beds or were trapped in log booms in log storage areas, or around reefs as in Fig. 3b).

Although the ambiguity in coastline definition accounts for the drop-off at the left side of the distance distribution (Fig. 4a), it does not explain the apparent tendency for drifters to be located within $50 \mathrm{~m}$ of the coast at nearly double the frequency that they are seen further offshore. However, if objects are distributed uniformly over the water's surface, they will not be distributed uniformly as a function of offshore distance.

To further investigate this distribution for the Salish Sea, a uniform grid of points was placed over a map of this region, and distances to the coast for all points in this grid were calculated and binned in the same way as for our drifter observations. The resulting synthetic distribution (Fig. 4a) closely matches the slope of the observed distribution for distances greater than $100 \mathrm{~m}$, showing a near-identical slow rise as distances decrease. However, it fails to capture the steep rise in the observed distribution at smaller distances. Thus, the drifter dataset is extensive enough to replicate the effects of a uniform spatial distribution of observations at large distance from the coast, in spite of a less-than-uniform distribution of points in the Salish Sea (Fig. 1a), but the observed tendency of drifters to preferentially stay within about $50 \mathrm{~m}$ of the coast probably results from dynamical and not purely geometrical considerations. Drifters tend to migrate inshore and spend more time closer to the coast.

Finally, the distribution of points within $10 \mathrm{~min}$ of grounding can also be obtained (Fig. 4a). These points mostly occur within $50 \mathrm{~m}$ of the coastline. The height of the distribution is about $10 \%$ of that for all points, suggesting that the probability of grounding within $10 \mathrm{~min}$ is only about $10 \%$, even for drifters near the coast. More will be said about this later.

\section{b. Drifter speeds near the coast}

In addition to determining the distance to the coastline, the velocity of the drifters at each observation point is estimated from position information by taking a centered difference in time. These velocities are then resolved into alongshore (coast on left) and offshore (negative for onshore) components $V_{a}$ and $V_{o}$, respectively, and binned by distance $x$ offshore.

Within each bin, velocities are widely scattered. However, mean offshore velocities $\left\langle V_{o}(x)\right\rangle$ are $(-7.6 \pm 0.8) \times 10^{-3} \mathrm{~m} \mathrm{~s}^{-1}$ for distances less than $700 \mathrm{~m}$ (Fig. 5a). Since drifters ground and are removed from our dataset, there must be a nonzero mean onshore velocity. The onshore velocities of points within 10 min of grounding are much larger, with a mean that grows linearly with distance to about $0.06 \mathrm{~m} \mathrm{~s}^{-1}$ at $100 \mathrm{~m}$ offshore.

This mean is not enough to actually reach the nominal coast from that distance in $10 \mathrm{~min}$. However, the 10 -min sampling is often not enough to fully sample small-scale variations in currents near the shore. In many situations the coastline is not parallel to the flow, which tends to be mostly alongshore, so that drifters can ground further along the coast where the coastline curves outwards.

Mean alongshore velocities $\left\langle V_{a}(x)\right\rangle$ are essentially zero for distances less than $400 \mathrm{~m}$, and only about $0.01 \mathrm{~m} \mathrm{~s}^{-1}$ with the coast on the right at distances of $400-1000 \mathrm{~m}$ (Fig. 5a). Although mean estuarine surface flows in this area can be as large as $0.2 \mathrm{~m} \mathrm{~s}^{-1}$ (Pawlowicz et al. 2019), and tidal currents in some places can be as much as an order of magnitude larger, the observations of alongshore flow average over tidal direction and coastline orientation relative to the mean flow.

Going beyond simple means, consider the near-coastal alongshore currents to be a mix of left- and rightward flows of roughly equal strength occurring at different times (e.g., during flood and ebb tides), with zero mean. Over a period of an hour or so there is a quasi-steady mean flow, which contains turbulent fluctuations at shorter time scales that are assumed to be proportional to the magnitude of the mean flow. Then the alongshore flow can be modeled with a unidirectional mean spatial structure $\bar{U}(x)>0$ and high-frequency turbulent fluctuations $U^{\prime}(x, t)$, both varying as a function of offshore distance $x$, whose sum is also unidirectional at any one time, modulated sinusoidally in a quasi-steady manner by the tide. That is,

$$
V_{a}(x, t) \approx\left[\bar{U}(x)+U^{\prime}(x, t)\right] \frac{\pi}{2} \sin (\omega t), \quad \bar{U}>0, \quad \bar{U}+U^{\prime}>0
$$

with $\omega$ the tidal frequency. By taking absolute values and time averages, it can be shown that $\left\langle\left|V_{a}\right|\right\rangle \approx \bar{U}(x)$. Thus, it is possible, in theory at least, to estimate a mean alongshore flow structure from a suitable average over the whole dataset.

The mean speed profile $\bar{U}(x)$ estimated in this way is a relatively smooth function of distance, with a speed of around $0.05 \mathrm{~m} \mathrm{~s}^{-1}$ right at the coast, growing to $0.27 \mathrm{~m} \mathrm{~s}^{-1}$ at an offshore distance of $1000 \mathrm{~m}$ (Fig. 5b). The mean alongshore speed structure at distances of $50-700 \mathrm{~m}$ is well described by

$$
\bar{U}(x) \approx 0.066 \times \log (x / 13 \mathrm{~m}) \mathrm{m} \mathrm{s}^{-1} .
$$

At greater distances, mean speeds are roughly constant, well below this logarithmic curve. Objects inshore of $50 \mathrm{~m}$, in addition to being more likely than one might expect from geometric considerations (Fig. 4a), have speeds well above the logarithmic curve. A logarithmic variation in speed is often seen in flows near walls and the implications of this will be discussed later.

It is difficult to directly estimate the strength of eddy fluctuations $U^{\prime}$ about the mean speed profiles in the alongshore direction. However, assuming that the turbulent eddies are roughly isotropic in the horizontal plane, alongshore fluctuations 

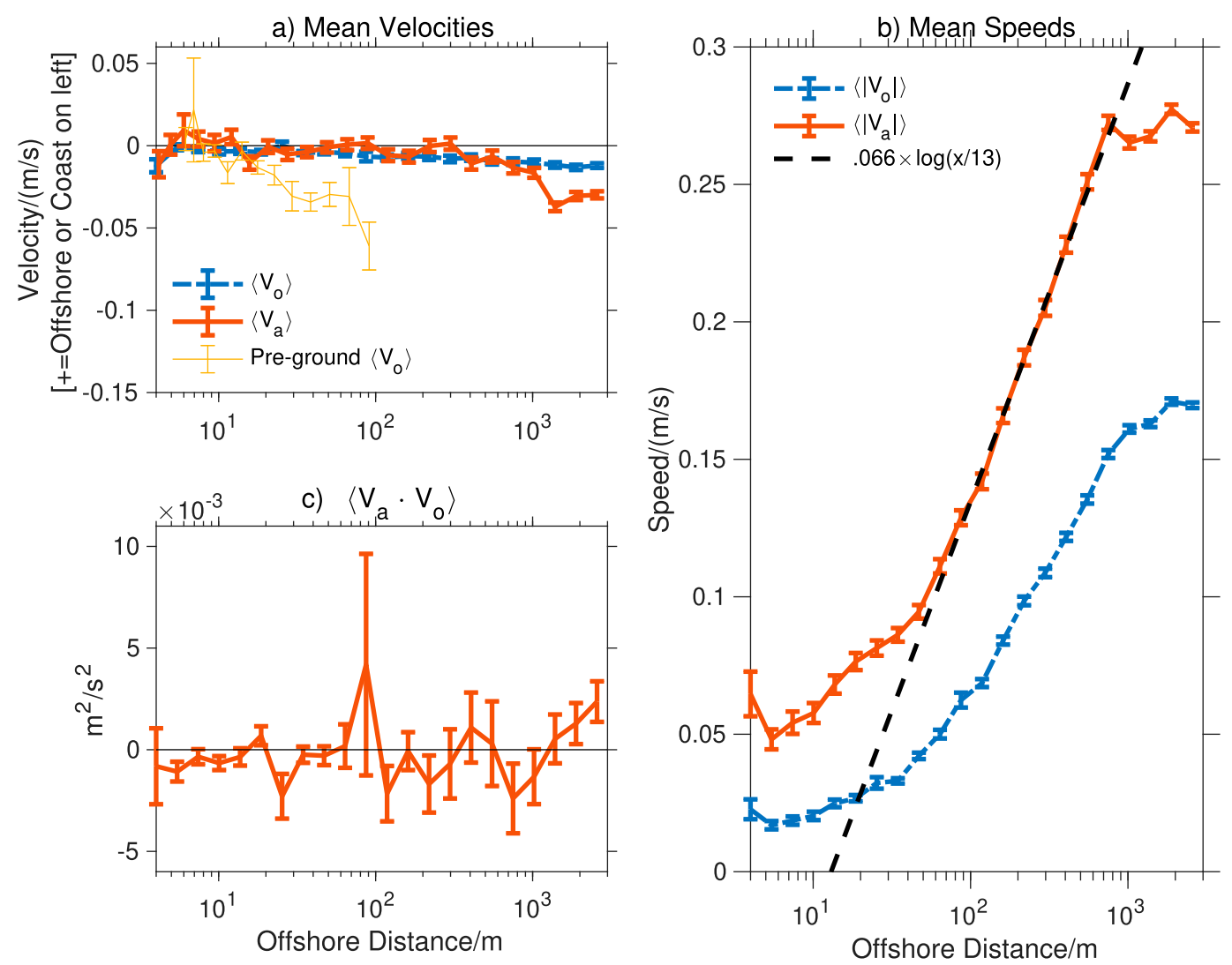

FIG. 5. Velocity structure near shore. (a) Mean velocities as a function of offshore distance. (b) Mean speeds as a function of offshore distance. (c) Eddy covariances. Error bars are the uncertainty in the mean calculated by taking the standard deviation of all $N$ points in a bin and dividing by $\sqrt{N}$, which varies from 10 at smallest distances to 120 at $1 \mathrm{~km}$ due to logarithmic increase in bin widths.

$U^{\prime}$ should be similar in magnitude to offshore fluctuations $V^{\prime}$. If, following Eq. (1), we also assume

$$
V_{o}(x, t) \approx\left[\bar{V}+V^{\prime}(x, t)\right] \frac{\pi}{2} \sin (\omega t)
$$

but with $|\bar{V}| \ll\left|V^{\prime}\right|$ then $\left\langle\left|V_{o}\right|\right\rangle \approx\left\langle\left|V^{\prime}\right|\right\rangle \approx\left\langle\left|U^{\prime}\right|\right\rangle$. The mean magnitude of turbulent fluctuations estimated in this way is small near the coast, and increases offshore (Fig. 5b), but is only about half the size of $\bar{U}$. Thus, the initial assumption in this analysis, i.e., that the alongshore flow (including any turbulence) is unidirectional at any one time, does not lead to inconsistencies.

Finally, the covariance between the alongshore and offshore current fluctuations can be calculated. Under the assumptions given above, $\left\langle V_{a} V_{o}\right\rangle \approx\left\langle U^{\prime} V^{\prime}\right\rangle \times \pi^{2} / 8 \approx\left\langle U^{\prime} V^{\prime}\right\rangle$. The mean covariance for distances of $50-700 \mathrm{~m}$ within the logarithmic regime is $(-0.4 \pm 0.8) \times 10^{-3} \mathrm{~m}^{2} \mathrm{~s}^{-2}$ (Fig. $5 \mathrm{c}$ ), i.e., negative, but with an uncertainty that includes zero.

\section{c. Time of grounding}

The tidal range in the Salish Sea is more than $3 \mathrm{~m}$, and tides have a complicated spatial pattern which differs for the diurnal and semidiurnal species (Foreman et al. 1995). Fortunately, reasonably accurate hindcast predictions are available from the SalishSeaCast model over the whole area, involving both astronomical and storm-surge related components. For every grounding, the tidal height, at the same time and nearest grid location (interpolating from the hourly fields to the exact times) was extracted, and the vertical velocity of the water surface obtained by differencing the hourly levels bracketing the exact time; 745 matches were found within the model grid.

There is a tendency for groundings to occur when water levels are high. A histogram-based probability density function (PDF) estimate of the height at grounding is skewed, with $66 \%$ of groundings at water levels above mean and $34 \%$ at levels below mean (Fig. 6a). However, the tidal heights themselves are not evenly distributed. A histogram-based PDF estimate of water level derived from all height data within 25 -h windows at each grounding location and centered at the grounding times (thus accounting for any bias that arrives from sampling at particular stages in the fortnightly cycle of tidal amplitudes) is similarly skewed, but with only $58 \%$ of values above the mean. A two-sample Kolmogorov-Smirnov goodness-of-fit hypothesis test rejects a null hypothesis of equal cumulativedistribution functions with $p=2.8 \times 10^{-7}$, but the mean height at grounding for all drifters is only $0.2 \mathrm{~m}$, not very different from zero. 

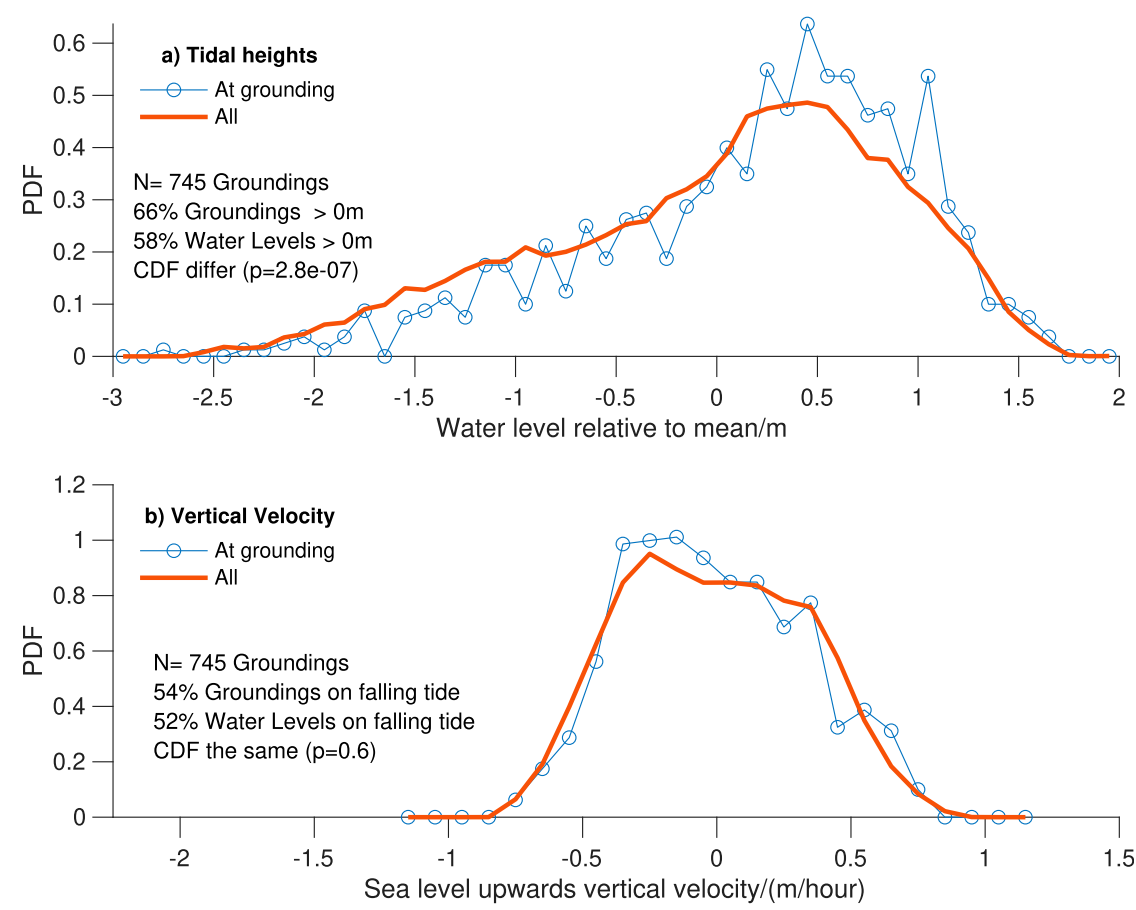

FIG. 6. PDF estimates of (a) grounding times with respect to water level, and (b) grounding times with respect to water surface vertical velocity. In both cases PDF estimates for all water levels and vertical velocities are also provided.

Are groundings more likely while water levels are falling relative to times when they are rising? A histogram-based PDF estimate of vertical velocities at grounding times (Fig. 6b) is relatively symmetric, with $54 \%$ of groundings occurring on a falling tide. In comparison, over all 25 -h windows at each grounding location, $52 \%$ of the time the tide itself is falling. In this case the two-sample Kolmogorov-Smirnov goodness-of-fit hypothesis test easily accepts the null hypothesis of both cumulative distribution functions being the same with $p=0.6$.

\section{d. Probability of grounding}

Since the influence of the tide on grounding appears to be somewhat weak, it seems reasonable to assume that at lowest order it is unimportant, i.e., that grounding is a stationary statistical process. The probability of grounding within $10 \mathrm{~min}$, when at a distance $x_{0}$ from the shore, denoted $P_{g}\left(x_{0}, 0<t<10\right)$, is then simply estimated by dividing the number of observations at a distance from the coast $x_{0}$ within $10 \mathrm{~min}$ of grounding by the total number of observations at $x_{0}$ (both shown in Fig. 4a, with the resulting probability estimates in Fig. 7a).

Similarly, all points that are between 10 and $20 \mathrm{~min}$ from grounding can be identified, and those between 20 and $30 \mathrm{~min}$, and so on, from the dataset. Dividing the number of these points at a given distance by our total number then provides estimates of $P_{g}\left(x_{0}, 10<t<20\right), P_{g}\left(x_{0}, 20<t<30\right)$, etc. (Figs. 7b-e).

Overall, empirical grounding probabilities are high at small time intervals when $x_{0}$ is small, peaking at around 0.1 within $10 \mathrm{~min}$ for drifters within $20 \mathrm{~m}$ of the shore (Fig. $7 \mathrm{a}$ ).
The probability of grounding decays as offshore distance increases, and grounding within $10 \mathrm{~min}$ is rare for distances beyond $100 \mathrm{~m}$. At larger times, the grounding probability in these 10-min intervals becomes smaller near the coast, but larger offshore. The general evolution of the grounding probabilities is somewhat reminiscent of a diffusion process.

\section{e. Eddy diffusivity}

Anticipating that this diffusion could arise from small-scale eddy processes in an as-yet undefined way, the eddy diffusivity in the Salish Sea is now estimated using standard procedures. At small scales, the divergence of pairs of drifters follows

$$
\kappa=\frac{1}{2} \frac{d}{d t} \overline{y^{2}}
$$

(LaCasce 2008), where $y$ is the distance between pairs and $\kappa$ the eddy diffusivity. Within the whole dataset there are 32 examples where multiple drifters were released from the same location at the same time in the Salish Sea, giving 96 comparable pairs. This set of paired separations represents conditions relatively far from the coast within more open waters.

Notwithstanding the fact that the separation time series do not all begin at a distance of zero, due to both the uncertainties arising from the unsynchronized sampling of positions, and the inevitable issues that arise during deployments at sea, the rootmean-square separation distance (Fig. 8) slowly increases to about $80 \mathrm{~m}$ in an hour, and $160 \mathrm{~m}$ in $2 \mathrm{~h}$ (with uncertainties of around $15 \%$ ). If the eddy diffusivity $\kappa$ is constant, then the root-mean-square separation distance should increase with 

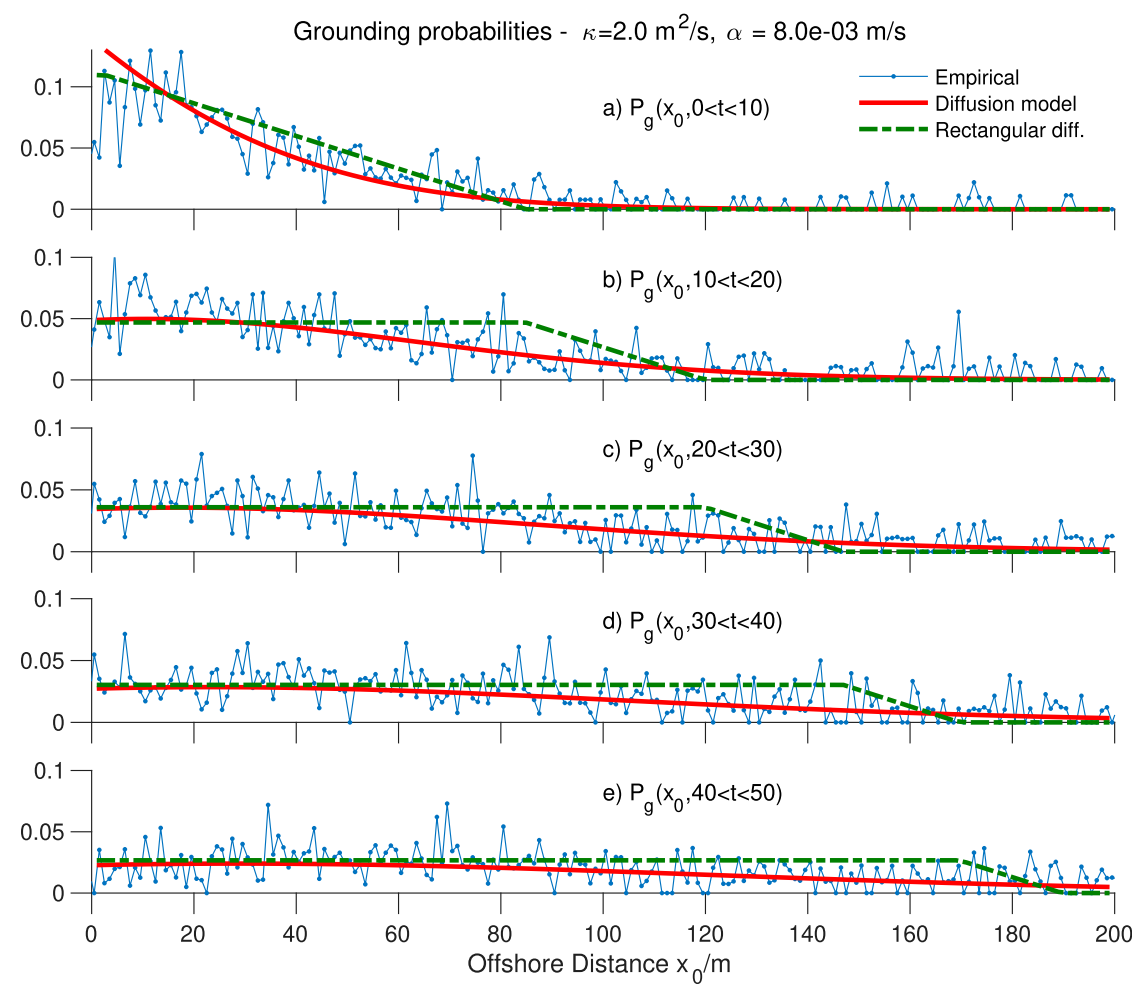

FIG. 7. Empirical grounding probabilities for the Salish Sea dataset, as well as the curves resulting from our two-parameter fit (thick solid), and those from the rectangular dispersion model (thick dashed).

time $t$ as $\sqrt{2 \kappa}$. A value of $\kappa \approx 1 \mathrm{~m}^{2} \mathrm{~s}^{-1}$ explains the observed rates of separation over the first few hours.

\section{Discussion}

The analyses described above proceeded under the a priori assumption that statistical structures could be found underlying the grounding process in spite of the complex nature of coastlines, especially in this region. Somewhat to my surprise (thus providing the motivation for this paper), the empirically determined grounding probability distribution (Fig. 7), and the near-coast velocity structures (Fig. 5), are not just "noise," but have well-defined coherent structures. Although the observational dataset includes two different drifter designs, the results from considering groundings for each design separately are almost identical, albeit with larger error bars arising from the smaller number of observations, so I have presented only pooled results here.

Speeds decrease closer to the coastline logarithmically from some offshore value, and drifters tend to accumulate inshore of this decrease, perhaps recirculating within near-coastal eddies. Drifters then ground. There is a slight tendency for this to occur near high water, but in general grounding can happen at any time. For drifters near the coast, the probability of grounding within a fixed time interval is highest at short times. At longer times this probability decreases. Further away from the coast, the probability of grounding is small for short times, reaches a maximum at some longer time, and then decreases again.

These structures are now interpreted more quantitatively using a variety of reasonably simple mathematical models.

\section{a. The coastal boundary layer}

A tendency for along-channel drifter speeds to decrease significantly closer to shore was recently noted in an analysis of drifters in a fjord system by Blanken et al. (2020), but their analysis did not consider the structure of this decrease. It is well known (Schlichting and Gersten 2017) that for turbulent flows over a surface, in conditions of neutral stability, the mean velocity profile $\bar{U}(x)$ with distance $x$ perpendicular to the surface has a logarithmic shape:

$$
\bar{U}(x)=\frac{u^{*}}{\kappa_{K}} \log \left(x / x_{r}\right),
$$

where $\kappa_{K} \approx 0.4$ is the Kármán constant, and $u^{*}=\sqrt{\tau / \rho}=$ $\sqrt{-\left\langle u^{\prime} v^{\prime}\right\rangle}$ is the friction velocity, with $\tau$ is the approximately constant Reynolds stress that arises from correlated turbulent velocity fluctuations $u^{\prime}$ and $v^{\prime}$ parallel and perpendicular to the surface, respectively, and $\rho$ the density. Parameter $x_{r}$ is an integration constant called the roughness length.

The scaling arguments that give rise to this log-layer can equally well be applied to the side boundary in a turbulent flow, especially if the flow is stratified so that the surface flow is not affected by bottom friction offshore, and the bottom 


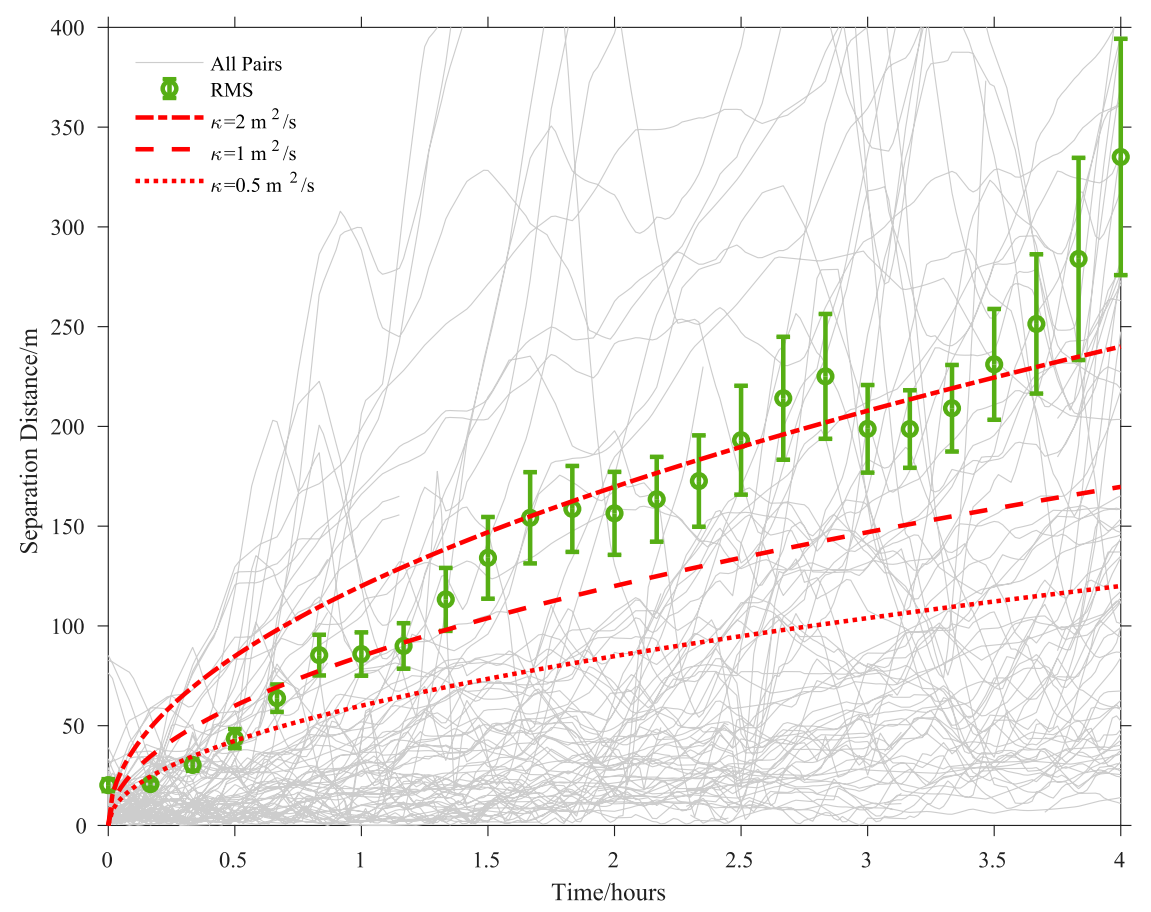

FIG. 8. The separation distance between pairs of drifters deployed simultaneously, as well as theoretical curves for various eddy diffusivities. Uncertainty in the RMS value has been bootstrapped, and calculations do not include one outlier curve that greatly affects the results at times greater than $3 \mathrm{~h}$.

near the coast slopes steeply enough to be considered "vertical." The logarithmic shape of the mean speed profile, at least for distances greater than $50 \mathrm{~m}$, has already been empirically demonstrated (Fig. 5b). However, the empirically determined fit parameters can also be shown to be reasonable based on their physical meaning in loglayer theory.

First, the multiplicative scale factor is related to the shear stress. The shear stress can be estimated from the mean eddy covariance (Fig. 5c), which was found to be $(-0.4 \pm 0.8) \times$ $10^{-3} \mathrm{~m}^{2} \mathrm{~s}^{-2}$. This range does not exclude positive values, but ignoring the uncertainty,

$$
\frac{u^{*}}{\kappa_{K}} \approx \frac{\sqrt{-\left\langle U^{\prime} V^{\prime}\right\rangle}}{0.4} \approx 0.05 \mathrm{~m} \mathrm{~s}^{-1},
$$

which agrees quite well with the fitted value of $0.066 \mathrm{~m} \mathrm{~s}^{-1}$.

Second, the roughness length is a fitting parameter that is typically very much smaller than the physical extent of the surface roughness elements. For flows over natural structures of height $L, x_{r} \approx 0.1 L$ (Fang and Sill 1992), although there is an order of magnitude range (from 0.03 to 0.3 ) in the scaling factor depending on the spacing and aspect ratio of the structures. Our fitted value of $13 \mathrm{~m}$ would then imply a "coastline roughness" of $O(130) \mathrm{m}$. It is not clear to what coastline parameter this could be compared, but it would be difficult to argue that our coastlines are smooth enough that all indentations are only $13 \mathrm{~m}$ in extent, conversely, an indentation scale of $1.3 \mathrm{~km}$ is perhaps equally unrealistic for the coastlines in this region. Thus, the fitted roughness length is arguably of a reasonable order for the geometry of our coastline.

There is therefore a satisfactory agreement between the measurements and many aspects of log-layer theory. However, it should be noted that the upper limit of the agreement at about $700 \mathrm{~m}$ offshore is less than an order of magnitude larger than the $\sim 130-\mathrm{m}$ scale size of coastline roughness elements implied by our empirical roughness length of $13 \mathrm{~m}$. Also, mean alongshore flows do not go to zero at the coast, as they would in the viscous sublayer of a true wall-flow. Finally, velocities sampled by Lagrangian particles can be biased by a tendency to accumulate in convergence zones, and the magnitude of this effect, if present, is not known. Fortunately, agreement with log-layer theory is not necessary for the next part of the analysis.

\section{b. The grounding process}

Turning to the grounding probabilities, assume that embedded in a large-scale dispersion representing the tidal and estuarine flow is a "subgrid-scale" eddy diffusive process that governs the actual grounding over short time scales, before the large-scale motion can take the drifting object far offshore again. Thus, imagine here an object starting location which is close to a relatively straight section of coast (i.e., at time $t=0$ an object is a distance $x_{0}$ away from the coast at $x=0$ ). The large-scale currents will be along the coastline here by continuity (any Stokes drift effect from onshore wave fields is ignored at this point, since-as was described earlier-these speeds are generally very small in the Salish Sea), but in addition to 
this large-scale flow imagine that small-scale turbulent features in the flow are also moving the drifting object either inshore or offshore. Modeling this turbulent dispersion as an (eddy) diffusive process, the probability density function (PDF) representing the object's offshore location, $p\left(x, t ; x_{0}\right)$ or just $p(x, t)$, will be governed by

$$
\frac{\partial p}{\partial t}=\kappa \frac{\partial^{2} p}{\partial x^{2}}, \quad x>0, \quad t>0
$$

with an initial distribution of $p(x, 0)=\delta\left(x-x_{0}\right)$ and offshore condition $p \rightarrow 0$ as $x \rightarrow \infty$.

The eddy diffusivity $\kappa$ is assumed constant. This is slightly inconsistent with the dynamics of a log-layer, but not only is it mathematically more convenient, more complex structures often do not give results that vary noticeably from this simple case (Csanady 1973), and, since our largest grounding probabilities occur within $100 \mathrm{~m}$ of the shore (mostly inshore of the fitted log-layer) it is not clear that a more complex structure is even justified.

Now, at the coastline $x=0$, the process of grounding means there is a flux of probability $\kappa \partial p / \partial x$ leaving the domain. This is parameterized as some fraction $\alpha$ of the probability density at that point:

$$
\kappa \frac{\partial p}{\partial x}(0, t)=\alpha p(0, t)
$$

where $\alpha$ has units of velocity; it represents the mean onshore velocity of diffusing objects. This provides a boundary condition at the coast.

Finally, the cumulative probability of grounding in some time interval $0 \leq t \leq T$, after starting at location $x_{0}$, will just be the time integral of the grounding flux over that interval:

$$
P_{g}\left(x_{0}, 0 \leq t \leq T\right)=\int_{0}^{T} \kappa \frac{\partial p}{\partial x}(0, t) d t=\alpha \int_{0}^{T} p(0, t) d t .
$$

This problem can be solved analytically using Laplace transforms for the time coordinate, with relevant transform pairs listed in Carslaw and Jaeger (1959). The solution is

$$
\begin{aligned}
p(x, t)= & \frac{1}{\sqrt{4 \kappa \pi t}} \exp \left[-\frac{\left(x_{0}-x\right)^{2}}{4 \kappa t}\right]+\frac{1}{\sqrt{4 \kappa \pi t}} \exp \left[-\frac{\left(x_{0}+x\right)^{2}}{4 \kappa t}\right] \\
& -h \exp \left[h\left(x_{0}+x\right)+\kappa t h^{2}\right] \operatorname{erfc}\left\{\frac{x_{0}+x}{\sqrt{4 \kappa t}}+h \sqrt{\kappa t}\right\}
\end{aligned}
$$

with $h=\alpha / \kappa$, and in turn

$$
\begin{aligned}
P_{g}\left(x_{0}, 0 \leq t \leq T\right)= & \operatorname{erfc}\left\{\frac{x_{0}}{\sqrt{4 \kappa T}}\right\}-\exp \left[h x_{0}+\kappa T h^{2}\right] \\
& \times \operatorname{erfc}\left\{\frac{x_{0}}{\sqrt{4 \kappa T}}+h \sqrt{\kappa T}\right\} .
\end{aligned}
$$

An example, which uses parameters that (as will be shown later) fit well with the Salish Sea dataset, illustrates the behavior of these formulas. At small times the grounding probability density (Fig. 9a) and cumulative grounding probabilities
(Fig. 9b) are small, because diffusion has not spread out the probability enough to reach the coastal boundary. Once enough diffusion has occurred, the PDF and associated grounding probabilities rise. However, at longer times, the probability density has diffused over a wide area, and the grounding fluxes become small again. The cumulative grounding probability rises relatively rapidly over a midrange in $T$, but the later approach to the final value of 1 is extremely slow. The asymptotic expansion of Eq. (11) at large times,

$$
P_{g}\left(x_{0}, 0 \leq t \leq T\right) \sim 1-\frac{x_{0}+\kappa / \alpha}{\sqrt{\pi \kappa T}}, \quad T \rightarrow \infty,
$$

which is a reasonable approximation for $P_{g} \gtrsim 0.6$ (Fig. 9b), shows that this approach is only proportional to $T^{-1 / 2}$.

The most likely grounding time (the mode of the PDF) is a few hundred seconds after a release at $50 \mathrm{~m}$ from the shore, but even after a day the total grounding probability is only about $60 \%$. This rises to only $80 \%$ after 3 days and $90 \%$ after $O(20)$ days. Of course, in a real tidal environment it seems unlikely that these high probability situations will be very relevant as the large-scale flow will probably advect away any particles before our assumed subgrid-scale processes can play a role.

A range of "probable" grounding times can be estimated more precisely. No grounding will occur before an object can diffuse close to the coastline, i.e., for $x_{0} / \sqrt{4 k T} \geqslant 1$. Similarly, at large $T$, the asymptotic expansion (12) can be used to find an expression for the time at which $P_{g} \approx 0.6$. Thus, most groundings occur at times in the range

$$
x_{0}^{2} /(4 \kappa) \leqq T \lesssim\left[\left(x_{0}+\kappa / \alpha\right) / 0.4\right]^{2} /(\pi \kappa),
$$

which for the parameters displayed in Fig. 9 is between about $5 \mathrm{~min}$ and 1 day. Since $\kappa / \alpha \approx 285 \mathrm{~m}$, this upper limit is somewhat insensitive to $x_{0}$ as long as $x_{0}<200 \mathrm{~m}$ or so. This matches anecdotal experience suggesting the drifter deployments should occur well offshore, since they otherwise often ground rapidly.

The analytical model has two adjustable parameters, $\alpha$ and $\kappa$. Setting $\alpha=0.008 \mathrm{~m} \mathrm{~s}^{-1}$ (which is essentially identical to the mean onshore velocity discussed in section $3 b$ ) and $\kappa=$ $2 \mathrm{~m}^{2} \mathrm{~s}^{-1}$ (very similar to the eddy diffusivity estimated offshore in section $3 \mathrm{e}$ ) results in an excellent fit (Fig. 7a). In terms of the wider applicability of these results, note that our observed "offshore" eddy diffusivity in the Salish Sea of $\sim 1 \mathrm{~m}^{2} \mathrm{~s}^{-1}$ is slightly higher than true open-ocean values, which over a scale of $500 \mathrm{~m}$ are more typically around $0.25 \mathrm{~m}^{2} \mathrm{~s}^{-1}$ (Okubo 1971).

Not only does Eq. (11) with these choices for the fit parameters match the empirical probabilities for drifters grounding within $10 \mathrm{~min}$, but it can also be compared with the empirical probabilities of grounding in successive 10-min intervals, after noting that $P_{g}\left(x_{0}, t_{1}<t<t_{2}\right)=P_{g}\left(x_{0}, 0<t<t_{2}\right)-P_{g}\left(x_{0}, 0<\right.$ $\left.t<t_{1}\right)$. With the same $\alpha$ and $\kappa$, the correspondence remains very good (Figs. 7b-e). The fit appears to be least accurate at distances of less than about $10 \mathrm{~m}$ in the first $10 \mathrm{~min}$. However, as discussed earlier, there are considerable difficulties in properly estimating offshore distance at these scales; the poor 

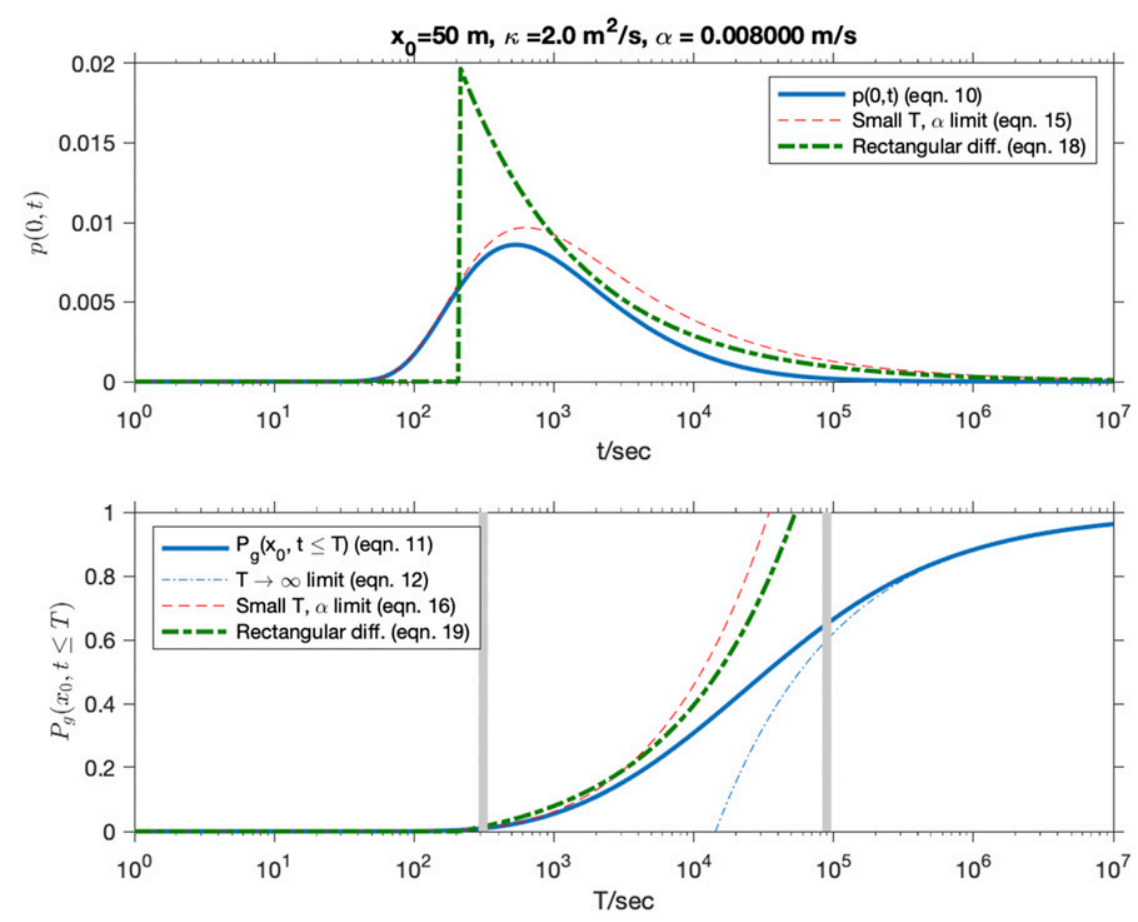

FIG. 9. An example of both (a) the PDFs at the coastal boundary $p(0, t)$, and (b) the cumulative grounding probabilities $P_{g}(t \leq T)$. The vertical lines in (b) indicate the range of grounding times given in Eq. (13).

fit there is then likely a result of problems with the data rather than with the model.

\section{c. Improved model parameterizations}

Can these results be used to improve grounding parameterizations in numerical trajectory modeling? Equation (11) is both computationally intensive and analytically awkward. However, note that at small $T$ and small $\alpha$, the object PDF at the coastline is

$$
p(0, t) \approx \frac{1}{\sqrt{\kappa \pi t}} \exp \left[-\frac{\left(x_{0}\right)^{2}}{4 \kappa t}\right]+O(\alpha),
$$

which at leading order is equal to

$$
\hat{p}(x, t) \approx \frac{1}{\sqrt{\kappa \pi t}} \exp \left[-\frac{\left(x_{0}-x\right)^{2}}{4 \kappa t}\right]
$$

at $x=0$ (Fig. 9a). Working backward, this can be recognized as a solution to Eq. (7) over an infinite domain with an initial condition of $\hat{p}(x, t)=2 \delta\left(x_{0}-x\right)$, i.e., a problem which ignores the existence of a coastline, at the cost having $\int \hat{p} d x=2$, so that this new problem does not, strictly speaking, model probabilities any longer. However, under these conditions the grounding flux can still be approximated, to leading order, as $\alpha \hat{p}(0, t)$.

In practical computational terms, this means that in order to predict groundings, it is not necessary to solve a boundary value problem on the semi-infinite domain to estimate whether an object will ground in some future time $t \leq T$. Instead it is only necessary to find some convenient approximation to $p$ which may be easier to compute.

As an example, an ad hoc grounding procedure might merely replicate an eddy diffusion process that ignores the presence of the boundary, but counts the drifter as grounded if at some point it diffuses over the coastline. Then analytically integrating (15),

$$
\begin{aligned}
P_{g}\left(x_{0}, 0 \leq t \leq T\right)= & 2 \alpha\left\{\sqrt{\frac{T}{\pi \kappa}} \exp \left(-\frac{x_{0}^{2}}{4 \kappa T}\right)\right. \\
& \left.-\frac{x_{0}}{2 \kappa} \operatorname{erfc}\left(\frac{x_{0}}{\sqrt{4 \kappa T}}\right)\right\},
\end{aligned}
$$

and this approximation seems to hold reasonably well as long as $P_{g} \lesssim 0.5$ (Fig. 9b).

More typically, for computational reasons uniform random variables are preferred over those with Gaussian distributions. Thus, let us crudely model diffusion as the evolution of a region of uniform density that grows with time (call this "rectangular diffusion"):

$$
p(x, t)=\left\{\begin{array}{cc}
\frac{1}{\sqrt{6 \kappa t}}, & \left|x-x_{0}\right| \leq \sqrt{6 \kappa t} \\
0, & \left|x-x_{0}\right|>\sqrt{6 \kappa t}
\end{array},\right.
$$

which has a variance of $\sqrt{2 \kappa t}$ to match the variance of Eq. (15), and $\int p d x=2$ as per the discussion following Eq. (15) so that 


$$
p(0, t)=\left\{\begin{array}{cc}
0, & t<x_{0}^{2} /(6 \kappa) \\
\frac{1}{\sqrt{6 \kappa t}}, & t \geq x_{0}^{2} /(6 \kappa)
\end{array},\right.
$$

and thus

$$
\begin{aligned}
& P_{g}\left(x_{0}, 0 \leq t \leq T\right) \\
& =\left\{\begin{array}{cl}
0, & x_{0}>\sqrt{6 \kappa T} \\
{\left[\frac{1}{2}\left(1-\frac{x_{0}}{\sqrt{6 \kappa T}}\right)\right]\left(\alpha \sqrt{\frac{8 T}{3 \kappa}}\right),} & x_{0}<\sqrt{6 \kappa T}
\end{array} .\right.
\end{aligned}
$$

This crude approximation results in a curve that maps reasonably well against our theoretical results for $P_{g} \lesssim 0.5$ (Fig. 9b), although it underestimates grounding probabilities at very early times (Fig. 9a). In addition, when we use the same $\kappa$ and $\alpha$ parameters obtained from the fit with the full model, this simple model still provides a very reasonable approximation to the empirical PDFs for our Salish Sea dataset (Fig. 7), at least for time steps $T$ that satisfy $\alpha \sqrt{8 T / 3 \kappa} \approx 0.0081 \sqrt{T} \lesssim 1$ or $T \lesssim 1.5 \times 10^{4} \mathrm{~s}$ (about $4 \mathrm{~h}$ ).

Note also that the probability in Eq. (19) is written as the product of two terms. The 1 st term can then be recognized as equivalent to the probability that adding a uniformly distributed random variable lying in the range between $-\sqrt{6 \kappa T}$ and $+\sqrt{6 \kappa T}$ to an object's offshore distance will result in a point on the land side of a coastline. The second term could then represent the probability that a particle is "sticky" at that particular coastline if it does end up on land. The stickiness increases with time spent in the vicinity of the coast, but decreases as the subgrid-scale diffusivity increases. The mean onshore velocity $\alpha$ parameterizes the nature of the coast. It might be zero at a vertical wall, for example, or perhaps somewhat larger than the value found here in regions with many small-scale features-rocks, mangrove forests, etc.- - that could trap floating objects.

A grounding prediction for a particular object in a time $0 \leq$ $t \leq T$ could now be made by 1 ) adding a uniformly distributed random distance from a range of $[-\sqrt{6 \kappa T}, \sqrt{6 \kappa T}]$ to its current location, where the model time step is $T ; 2$ ) if the resultant point is now located over land, an additional uniform random variable over [0,1] is generated; and 3) if this value is less than stickiness $\alpha \sqrt{8 T / 3 \kappa}$, which itself must be less than 1 for validity of this approach, the drifter is classified as grounded. For hourly particle integration intervals, the Salish Sea stickiness is about 0.5 .

Note that the ad hoc grounding parameterizations due to subgrid-scale motion in some existing numerical codes (e.g., Zelenke et al. 2012; Lange and van Sebille 2017, and likely many others), carry out the first step of adding a random offset, but then simply classify the point as grounded if it ends up over land. This is essentially equivalent to assuming a stickiness of 1 .

An even simpler grounding model, used by Fernandes et al. (2013) is

$$
P_{g}\left(x_{0}, 0 \leq t \leq T\right)=\left\{\begin{array}{ll}
0, & x_{0}>D \\
\beta, & x_{0}<D
\end{array} .\right.
$$

with tuning parameters $D$ and $\beta$. Although no guidance is provided for these parameters, comparison with Eq. (19) suggests that setting $D \propto \sqrt{\kappa T}$ and $\beta \propto \alpha \sqrt{T / \kappa}$ will provide for the correct dependence on model time step and coastline stickiness through changes to $\beta$, which can be explicitly set to be different for different stretches of coastline, but its offshore structure is less realistic.

\section{Conclusions}

Although oceanographers are usually concerned with transport within the water column, there are many current problems that require understanding the way in which floating objects interact with the land (Van Sebille et al. 2020). This is a research topic that is somewhat understudied, likely because there has been no obvious way to gather large amounts of relevant data. However, the appearance of cheap tracking units which can be incorporated into small expendable drifters has opened this area up to further inquiry. Here a dataset of more than 800 groundings in the Salish Sea is examined to determine whether grounding can be described in a robust statistical manner.

As might be expected, the grounding process for individual drifters can be complex and highly variable. Two categories of grounding are used here (mostly touching ground but still moving, and mostly floating but trapped), and the distinction between the two cases and between grounded and freely floating situations often requires a manual determination. Surprisingly, however, suitable analyses do show that the complications of coastlines can be statistically summarized in rather standard ways. First, the velocity structure approaching the coast suggests a classic "log-layer" associated with coastline friction, at least in this deep stratified environment. Interestingly, drifters are almost twice as likely to be inshore of this region than might be expected if they were uniformly distributed over the water surface; and mean speeds in this area are also higher than expected from the log-layer theory (although lower than in the open ocean offshore). These speeds do not go to zero at the coast. It will be important to see if results are different in shallow, well-mixed coastal waters where bottom friction may be more important.

Second, although groundings are marginally more likely to occur at high tide, there are many counterexamples and the preference is not overwhelming. Simply ignoring tidal effects on grounding times is a reasonable approximation. Objects can ground on a falling tide by being stranded, but on a low or rising tide, a drifter may remain essentially grounded while being slowly pushed toward the high tide line.

Assuming stationarity, the actual grounding process itself is then well modeled using a classical eddy diffusivity formulation, and the relevant eddy diffusivity that results in the best match to the observed probabilities does not appear to be much different from that seen away from the coastline, and hence is capable of being measured at other locations away from the coast. A new parameter in this formulation is a mean shoreward velocity for floating objects, which could also (in theory at least) be measured offshore, but within the coastal boundary layer. It would be useful to gain a better understanding of the relationship between different coastline morphologies 
and this mean shoreward velocity. This would also require measurements in other regions.

Finally, it was shown that, under some restrictions, current ad hoc beaching parameterizations, although not, strictly speaking, firmly grounded in theory, should be relatively accurate in qualitative terms-that is, they can provide reasonable predictions about the likely places where particles ground, assuming the accuracy of the large-scale circulation and a suitable choice of the free parameters-but that they are unlikely to be accurate in quantitative terms, which may be required for the predictions of mass budgets and fluxes. Of course, in many situations the effects of windage and Stokes drift terms, which have been plausibly neglected for this dataset, may be more important than subgrid-scale diffusion in determining grounding probabilities.

Acknowledgments. Funding for this work was provided by Metro Vancouver and the Natural Sciences and Engineering Research Council of Canada under Grant CRDPJ 486139-15. This work required the assistance of many people in deploying the drifters, with special thanks to R. di Costanzo and K. Stankov for operating the UBC drifter program and C. Hannah, S. Page, and R. Hourston for the Fisheries and Oceans Canada program, S. Stevens for extracting tidal information for me, E. Mason for checking the math, and M. Wang for carrying out early explorations with grounding parameterizations in numerical drifter codes.

Data availability statement. High-resolution coastlines were obtained from the provincial government of British Columbia (https:/catalogue.data.gov.bc.ca/dataset/freshwater-atlas-coastlines) and the Washington State Department of Ecology (http:// www.ecy.wa.gov/services/gis/data/data.htm). SalishSeaCast hourly fields are archived and available at available at salishsea.eos.ubc.ca/ erddap. The drifter dataset is available from the Scholars Portal Dataverse at https://doi.org/10.5683/SP2/C8MJOA

\section{REFERENCES}

Blanken, H., C. Hannah, J. M. Klymak, and T. Juhász, 2020: Surface drift and dispersion in a multiply connected fjord system. J. Geophys. Res. Oceans, 125, e2019JC015425, https:// doi.org/10.1029/2019JC015425.

Carslaw, H. S., and J. C. Jaeger, 1959: Conduction of Heat in Solids. 2nd ed. Clarendon Press, 510 pp.

Csanady, G. T., 1973: Turbulent Diffusion in the Environment. Geophys. Astrophys. Monogr., No. 3, D. Reidel, 249 pp.

Ebbesmeyer, C. C., and W. D. Haglund, 2002: Floating remains on Pacific Northwest waters. Advances in Forensic Taphonomy: Method, Theory, and Archaeological Perspectives, W. D. Haglund, and M. H. Sorg, Eds., CRC Press, 219-239.

Fang, C., and B. Sill, 1992: Aerodynamic roughness length: Correlation with roughness elements. J. Wind Eng. Ind. Aerodyn., 41, 449-460, https://doi.org/10.1016/0167-6105(92)90444-F.

Fernandes, R., R. Neves, and C. Viegas, 2013: Integration of an oil and inert spill model in a framework for risk management of spills at sea: A case study for the Atlantic area. 36th AMOP Technical Seminar on Environmental Contamination and Response, Halifax, NS, Canada, Arctic Marine Oilspill Program, 326-353, https://doi.org/10.13140/2.1.1740.3200.
Foreman, M. G. G., R. A. Walters, R. F. Henry, C. P. Keller, and A. G. Dolling, 1995: A tide model for eastern Juan de Fuca Strait and the southern Strait of Georgia. J. Geophys. Res., 100, 721-740, https://doi.org/10.1029/94JC02721.

Gemmrich, J., and R. Pawlowicz, 2020: Wind waves in the Strait of Georgia. Atmos.-Ocean, 58, 79-97, https://doi.org/10.1080/ 07055900.2020 .1735989$.

Irfan, U., 2019: The human feet that routinely wash ashore in the Pacific Northwest, explained. Vox.com, 11 February 2019, https://www.vox.com/science-and-health/2017/12/18/16777724/ human-feet-beach-pacific-northwest-seattle-vancouver.

Jambeck, J. R., R. Geyer, C. Wilcox, T. R. Siegler, M. Perryman, A. Andrady, R. Narayan, and K. L. Law, 2015: Plastic waste inputs from land into the ocean. Science, 347, 768-771, https:// doi.org/10.1126/science.1260352.

Jansen, E., G. Coppini, and N. Pinardi, 2016: Drift simulation of MH370 debris using superensemble techniques. Nat. Hazards Earth Syst. Sci., 16, 1623-1628, https://doi.org/10.5194/nhess-16-1623-2016.

Kako, S., A. Isobe, T. Kataoka, and H. Hinata, 2014: A decadal prediction of the quantity of plastic marine debris littered on beaches of the East Asian marginal seas. Mar. Pollut. Bull., 81, 174-184, https://doi.org/10.1016/j.marpolbul.2014.01.057.

LaCasce, J., 2008: Statistics from Lagrangian observations. Prog. Oceanogr., 77, 1-29, https://doi.org/10.1016/j.pocean.2008.02.002.

Lange, M., and E. van Sebille, 2017: Parcels v0.9: Prototyping a Lagrangian ocean analysis framework for the petascale age. Geosci. Model. Devel., 10, 4175-4186, https://doi.org/10.5194/ gmd-10-4175-2017.

Lumpkin, R., N. Maximenko, and M. Pazos, 2012: Evaluating where and why drifters die. J. Atmos. Oceanic Technol., 29, 300-308, https://doi.org/10.1175/JTECH-D-11-00100.1.

_ T. Özgökmen, and L. Centurioni, 2017: Advances in the application of surface drifters. Annu. Rev. Mar. Sci., 9, 59-81, https://doi.org/10.1146/annurev-marine-010816-060641.

Masson, D., 2006: Seasonal water mass analysis for the Straits of Juan de Fuca and Georgia. Atmos.-Ocean, 44, 1-15, https:// doi.org/10.3137/ao.440101.

Meyerjürgens, J., T. H. Badewien, S. P. Garaba, J.-O. Wolff, and O. Zielinski, 2019: A state-of-the-art compact surface drifter reveals pathways of floating marine litter in the German bight. Front. Mar. Sci., 6, 58, https://doi.org/10.3389/fmars.2019.00058.

Milbrandt, J. A., S. Bélair, M. Faucher, M. Vallée, M. L. Carrera, and A. Glazer, 2016: The pan-Canadian high resolution $(2.5 \mathrm{~km})$ deterministic prediction system. Wea. Forecasting, $\mathbf{3 1}$, 1791-1816, https://doi.org/10.1175/WAF-D-16-0035.1.

Novelli, G., C. M. Guigand, C. Cousin, E. H. Ryan, N. J. Laxague, H. Dai, B. K. Haus, and T. M. Özgökmen, 2017: A biodegradable surface drifter for ocean sampling on a massive scale. J. Atmos. Oceanic Technol., 34, 2509-2532, https://doi.org/ 10.1175/JTECH-D-17-0055.1.

Okubo, A., 1971: Oceanic diffusion diagrams. Deep-Sea Res. Oceanogr. Abstr., 18, 789-802, https://doi.org/10.1016/0011-7471(71)90046-5.

Page, S., C. Hannah, T. Juhasz, D. Spear, and H. Blanken, 2019: Surface circulation tracking drifter data for the Kitimat Fjord system in northern British Columbia and adjacent continental shelf for April, 2014 to July, 2016. Canadian Data Report of Hydrography and Ocean Sciences 206, Fisheries and Oceans Canada, 33 pp.

Pawlowicz, R., 2019: M_Map: a mapping package for MATLAB, v1.4m. https://www.eoas.ubc.ca/ rich/map.html.

, O. Riche, and M. Halverson, 2007: The circulation and residence time of the Strait of Georgia using a simple mixing-box approach. Atmos.-Ocean, 45, 173-193, https://doi.org/10.3137/ao.450401. 
C. Hannah, and A. Rosenberger, 2019: Lagrangian observations of estuarine residence times, dispersion, and trapping in the Salish Sea. Estuarine Coastal Shelf Sci., 225, 106246, https://doi.org/10.1016/j.ecss.2019.106246.

Schlichting, H., and K. Gersten, 2017: Boundary-Layer Theory. 9th ed. Spring-Verlag, 805 pp.

Soontiens, N., and S. E. Allen, 2017: Modelling sensitivities to mixing and advection in a sill-basin estuarine system. Ocean Modell., 112, 17-32, https://doi.org/10.1016/j.ocemod.2017.02.008.

- and Coauthors, 2016: Storm surges in the Strait of Georgia simulated with a regional model. Atmos.-Ocean, 54, 1-21, https://doi.org/10.1080/07055900.2015.1108899.

Spaulding, M. L., 2017: State of the art review and future directions in oil spill modeling. Mar. Pollut. Bull., 115, 7-19, https://doi.org/ 10.1016/j.marpolbul.2017.01.001.
Van Sebille, E., and Coauthors, 2018: Lagrangian ocean analysis: Fundamentals and practices. Ocean Modell., 121, 49-75, https:// doi.org/10.1016/j.ocemod.2017.11.008.

— transport of floating marine debris. Environ. Res. Lett., 15, 023003, https://doi.org/10.1088/1748-9326/ab6d7d.

Yang, Z., G. García-Medina, W.-C. Wu, T. Wang, L. R. Leung, L. Castrucci, and G. Mauger, 2019: Modeling analysis of the swell and wind-sea climate in the Salish Sea. Estuarine Coastal Shelf Sci., 224, 289-300, https://doi.org/10.1016/j.ecss.2019.04.043.

Zelenke, B., C. O'Conner, C. Barker, C. Beegle-Krause, and L. Eclipse, 2012: General NOAA operational modelling environment (GNOME) technical documentation. NOAA Tech. Memo NOS OR\&R 40, 105 pp., https://response.restoration.noaa.gov/ sites/default/files/GNOME_Tech_Doc.pdf. 